\title{
A Further Study on the Compensatory Increase of the Adrenaline Content in the Adrenal Gland in Rabbits
}

\author{
By \\ Itiro Tano \\ (田 野 一 郎) \\ (From the Physiological Laboratory of Prof. Y. Satake, . \\ Tohoku University, Sendai)
}

(Received for publication, June 19, 1951)

While Stewart and Rogoff ${ }^{11}$ and others, who saw a copious compensatory increase of adrenaline in rabbits, estimated it with the Folin method, Ooisi' ${ }^{21}$ applied the Suto-Kojima's corrosive sublimate method, and came to discover its non-occurrence. The former procedure measures besides adrenaline the ascorbic acid which is much involved in the cortical tissue, and this increases copiously in compensation.

In order to testify whether the data obtained in the hands of Stewart and Rogoff are due solely to the compensatory increase of the substance which is Folin-positive, but not adrenaline, some rabbits were experimented on with quite the same planning and procedures as Ooisi, only with an addition of the Folin method, modified by Kodama. ${ }^{31}$

The removal of glands through the lumbar way, without narcosis, consumed 30-56 minutes, and the I and II extirpation were separated by an interval of 85-166 days. $10 \mathrm{cc}$. of Folin's extract was prepared from one gland, and $5 \mathrm{cc}$. was used for the Folin-Kodama, and $4 \mathrm{cc}$. for the Suto, practized according to Ooisi. The matching was carried out with a micro-colorimeter of Dubosque type.

All the outcome are epitomized in the accompanying table. The left gland was removed out at first from 7 rabbits, and the right one from 4. The days, separating two removals, were similar in both the series of experiments, and the increase, in the body weight in those days, that is, 119 days in both series, was about 20 percent similarly. The gain in the second glands was clearly large in the latter series, where the left gland was remaining behind.

In the first place, the Folin value was found largely increased in the glands, staying behind. The total amount increased by $50-100 \%$, and the value per $\mathrm{kg}$. of body weight also by the same rate. They are comprehensivable. Now the fact that the concentration of the Folin in the re- 
TABLE

Adrenaline Content in the Adrenals, Taken

Determination by the Suto

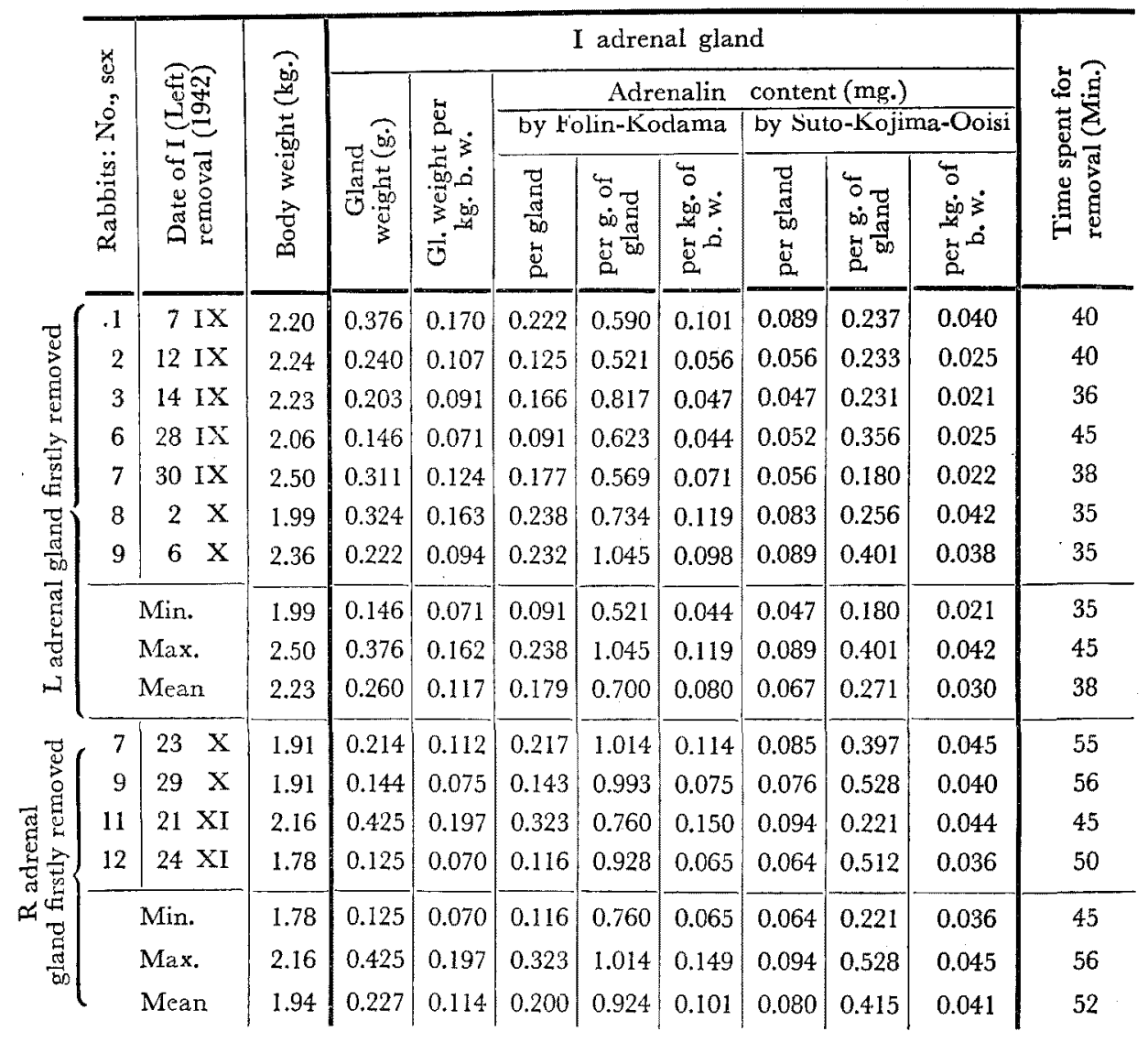

maining left glands in the latter set was about the half of the normal, right glands seems strange. It might be however accounted for by the fact that the left glands in this set were more rapidly, increasing in comparison with those in the first group, as just above referred to. The tissue is growing rapidly, so that it is not yet filled up witht the acid.

In the second place, the data on the adrenaline, measurable by the Suto-Kojima method will be discussed now. Look at for a moment first on the data in the latter series of experiments: The total amount of adrenaline was measured as increased and in fact in paralled to the gain in he body weight. That is, the amount of adrenaline, reckoned on $\mathrm{kg}$. body weight did not altered; about 0.041 and 0.043 they are. The concentration in the glands were estimated incomparatively thin; it might be howeyer commented on the behalf of the copious enlargement of cortical 
Out with Interval of Several Days

method and the Folin method.

\begin{tabular}{|c|c|c|c|c|c|c|c|c|c|c|c|c|}
\hline \multirow{4}{*}{\multicolumn{2}{|c|}{ 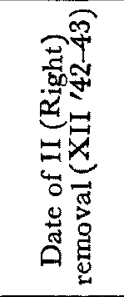 }} & \multirow{4}{*}{ 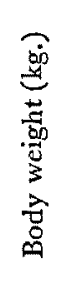 } & \multicolumn{8}{|c|}{ II adrenal gland } & \multirow{4}{*}{ 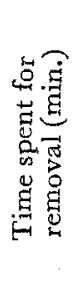 } & \multirow{4}{*}{ 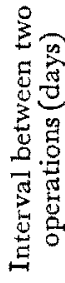 } \\
\hline & & & \multirow{3}{*}{ 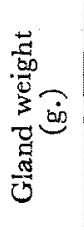 } & \multirow{3}{*}{ 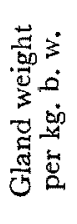 } & \multicolumn{6}{|c|}{ Adrenaline content } & & \\
\hline & & & & & \multicolumn{3}{|c|}{ by Folin-Kodama } & \multicolumn{3}{|c|}{ by Suto Kojima-Uoisi } & & \\
\hline & & & & & 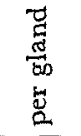 & 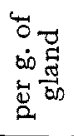 & 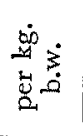 & 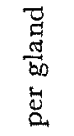 & 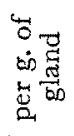 & 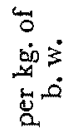 & & \\
\hline 1 & $\mathrm{XII}$ & 2.55 & 0.496 & 0.195 & 0.317 & 0.639 & 0.124 & 0.104 & 0.210 & 0.041 & 50 & 85 \\
\hline 25 & $\mathrm{I}$ & 2.67 & 0.414 & 0.155 & 0.476 & 1.150 & 0.178 & 0.112 & 0.271 & 0.042 & 50 & 135 \\
\hline 18 & XII & 2.64 & 0.344 & 0.131 & 0.312 & 0.907 & 0.118 & 0.120 & 0.349 & 0.045 & 45 & 95 \\
\hline 21 & I & 2.34 & 0.510 & 0.218 & 0.250 & 0.490 & 0.107 & 0.093 & 0.182 & 0.040 & 55 & 115 \\
\hline 15 & III & 3.02 & 0.580 & 0.192 & 0.266 & 0.459 & 0.088 & 0.096 & 0.177 & 0.032 & 36 & 166 \\
\hline 29 & I & 2.39 & 0.703 & 0.294 & 0.588 & 0.836 & 0.246 & 0.125 & 0.178 & 0.052 & 40 & 119 \\
\hline \multirow[t]{4}{*}{4} & II & 2.97 & 0.590 & 0.199 & 0.571 & 0.968 & 0.192 & 0.110 & 0.186 & 0.037 & 40 & 121 \\
\hline & & 2.34 & 0.344 & 0.131 & 0.250 & 0.459 & 0.088 & 0.093 & 0.178 & 0.037 & 36 & 85 \\
\hline & & 3.02 & 0.703 & 0.294 & 0.588 & 1.150 & 0.246 & 0.125 & 0.349 & 0.052 & 55 & 166 \\
\hline & & 2.65 & 0.519 & 0.198 & 0.397 & 0.778 & 0.150 & 0.109 & 0.220 & 0.041 & 45 & 119 \\
\hline 6 & III & 2.08 & 0.576 & 0.277 & 0.333 & 0.578 & 0.160 & 0.114 & 0.198 & 0.055 & 35 & 134 \\
\hline 27 & II & 2.56 & 0.468 & 0.183 & 0.200 & 0.427 & 0.078 & 0.085 & 0.182 & 0.033 & 32 & 121 \\
\hline 8 & III & 2.28 & 0.945 & 0.414 & 0.454 & 0.480 & 0.199 & 0.123 & 0.130 & 0.054 & 30 & 107 \\
\hline \multirow[t]{4}{*}{17} & III & 2.23 & 0.312 & 0.140 & 0.143 & 0.458 & 0.064 & 0.068 & 0.218 & 0.030 & 32 & 113 \\
\hline & & 2.08 & 0.312 & 0.139 & 0.143 & 0.427 & 0.064 & 0.068 & 0.130 & 0.030 & 30 & 107 \\
\hline & & 2.56 & 0.945 & 0.414 & 0.454 & 0.578 & 0.199 & 0.123 & 0.218 & 0.055 & 35 & 134 \\
\hline & & 2.29 & 0.575 & 0.254 & 0.283 & 0.486 & 0.125 & 0.098 & 0.182 & 0.043 & 32 & 119 \\
\hline
\end{tabular}

tissue in these cases, as shown just above.

Turning now to the data in the former set: The figures rê the amount of adrenaline in toto and its concentration in the glands harmonize with the above statement, but the values of adrenaline, reckoned on the body weight, are definitely smaller in the glands, removed out at first. The figures are enough to let us second to the view of the compensatory increase of the medulli-adrenal tissue, although the data in the latter half of the present investigation and in the paper of Ooisi do not so. A closer investigation points us a number of cases with an abnormally smaller storage of adrenaline; $0.0225 \mathrm{mg}$ per $\mathrm{kg}$. b. w. is a very seldom occurrence. ${ }^{4)}$ If such rather abnormal cases be taken out of consideration, the figure of per $\mathrm{kg}$ of body weight can be arranged as $0.04 \mathrm{mg}$. Then this set of experiments does not run out of the general inclination. And in doing so, 
the whole figures in the upper half of the table do not lose the harmony. Briefly stated: In rabbits an adrenal gland was removed out, and four months later the fellow gland was excised in a similar manner. The gland, extirpated later, increased largely in weight, and the Folin positive substance showed a similar inclination quantitatively, but it was occasioned solely or at least chiefly by the substance, non-identified with adrenaline, namely by ascorbic acid.

\section{References}

1) Stewart \& Rogoff, J. of Exp. Med., 1916, 24, $726 \mathrm{ff}$.

2) Ooisi, Tohoku J. of Exp. Med., 1942, 44, 321.

3) Kodama, J. of Biochem., 1922, 1, 281.

4) Sato, H., Iwate Igaku Semmon Gakko Zassi, 1940, 4, 242. 